The tyranny of ethics? Political challenges and tensions when applying ethical governance to qualitative social work research

Prof. Malcolm Carey

Faculty of Health and Social Care

University of Chester

Martin Building

Crab Lane

Fearnhead

Warrington

WA2 0DB

m.carey@ chester.ac.uk

\title{
Biography
}

Malcolm Carey is Professor of Social Work the University of Chester. He teaches both undergraduates and postgraduates on professional social work programmes and his principle research interests include adult social work and ageing, disability, applied ethics and qualitative research. 
The tyranny of ethics? Political challenges and tensions when applying ethical governance frameworks to qualitative social work research

\section{Malcolm Carey}

\section{Abstract:}

This paper examines problems which current ethical governance processes generate for qualitative researchers within social work. It draws upon case studies and critical theory to detail the unpredictable and diverse nature of much social work qualitative research. It argues that too often this research is pitted against a narrow institutional focus placed on positivist-orientated empirical research and income generation. Overtly instrumental interpretations of ethics - often determined by realist and bioethical paradigms - can quickly inhibit the methodological dynamism required to meaningfully capture the complex and non-binary issues which social workers accommodate in their work and subsequent research. Arguments that policy-led, institutional and professional cultures have generated a conservative culture of riskaversion within the neo-liberal university are also considered.

Keywords: ethics; governance; qualitative research; risk; neo-liberal university; bioethics. 


\section{The tyranny of ethics? Political challenges and tensions when applying ethical governance frameworks to qualitative social work research}

\section{Introduction}

For many years now, instrumental ethical governance frameworks have stringently regulated, and often restricted, the options available for staff and students to undertake qualitative research within social work. For example, students in the UK studying on many social work programmes are now encouraged to avoid undertaking empirical research for dissertations, and increasingly opt for literaturebased reviews to avoid time-consuming applications to any University Research Ethics Committees (URECs). Regulatory governance systems - such as the Integrated Research Application System (IRAS) within the National Health Service (NHS) - can again be time consuming and disheartening. Such examples often lead to researchers avoiding important topics of investigation, co-production or methodologies identified as sensitive or too difficult to navigate through over-zealous committees (for example, Truman, 2003; Fisher, 2012; Ward and Campbell, 2013; Parker and Ashencaen Crabtree, 2014; Dickson and Holland, 2017). Subsequently, many university-based researchers aiming to undertake qualitative research now view processes of ethical approval as representing an onerous hurdle to be carefully negotiated, rather than as constructive, engaging or helpful part of any research process. Indeed, as Dickson and Holland (2017: 134) surmise:

'Frustration with institutional research ethics regulation is a common experience for researchers in the humanities and social sciences... It is an 
experience shared across national borders, disciplines, institutions, theoretical and methodological approaches, types of research participants and topics of research'.

Other critics have emphasised the disengaged or disempowering impact of increased ethical governance processes upon service users within social and health care, while highlighting the power imbalances which institutional types of governance promote (Craig et al, 2014). This includes that the balance of power tends to be 'in favour of experts, rather than research participants' (Truman, 2003: 6). Power imbalances may also serve interests beyond ethical remits and any rational deliberations prioritised by URECs. These might include a range of measures which protect institutional interests, such as possible attempts made to reduce the risks of research participants pursuing litigation in relation to any distress experienced during involvement in research. Grant funders - including governments or institutions within education or welfare - can use ethical governance technologies to control and limit the publication of sensitive or embarrassing data, which may significantly undermine the principles of open debate and free speech. Ethical governance within universities and in the workplace can also provide a platform to extend the encroachment of New Public Management, regulate or discipline staff and even monitor teaching materials, thereby representing an effective 'means of internal social control' (Hedgecoe, 2016: 491).

The emergence of pernicious forms of ethical research governance is perhaps all the more ironic for social work, due to the relatively few numbers of small-scale empirical projects common within and around the profession (Dominelli and Holloway, 2008). This contrasts sharply with the more prevalent, often larger-scale and sometimes 
generously funded projects familiar in 'associate' helping professions such as healthcare. Subsequently, with potentially significant restraints placed on social work staff and students, there persists a continued realisation that any developing research culture within social work - including more critical projects - will be contained, or indeed shrink. Such concerns become more acute when links are drawn between qualitative research within UK universities and the apparent 'Stalinist policies' of aggressive audit, regulation and evaluation pursued for many years within the 'neoliberal university' (Parker and Jary, 1995; Bailey, 2014; Mountz et al, 2015; Ferreri and Glucksberg, 2016).

This paper looks at some of the problems and political implications which current frameworks of ethical governance generate for qualitative researchers within social work. It concentrates upon the UK but also uses examples of research projects from other countries. Among other findings, it details some prevailing practical and ideological controls which persist with regards ethical governance within institutions and disciplines. Power differences between social work, health care and medicine are also noted, including the tendency for the latter to increasingly influence ethical regulation and subsequent practice. Arguments that policy-led, institutional and profession cultures have generated a risk-averse culture which may promote a 'diminished self' are also discussed. The final section argues that in many instances with appropriate peer support if necessary, moral-self, peer and participative governance with co-researchers are likely to be as, or indeed more effective in promoting ethical research than committee-based techniques and regulation within or imposed upon social work.

\section{Practical problems within qualitative research}


The growth and influence of ethics committees to govern expanding research cultures has led to a significant demand for suitable levels of expertise. Despite such needs, membership of URECs still tend to be organised on a voluntary basis in many universities. Moreover, there is often little or no requirement that members' expertise encompasses the ever expanding, and often complex, fields of ethics and qualitative research methodology (Hammersley, 2009). In an era in which transdisciplinary and multi-professional research is actively promoted, volunteers may subsequently lack the essential knowledge or practical experiences relating to specific disciplines. Consequentially, alongside their peers, social work researchers can find that their projects are being evaluated from experts in fields as detached as physio-therapy, nursing or mathematics, among other examples. Hammersley (2009: 216) adds that ethics committee members are unlikely to each have the arguably essential full range of 'contextual knowledge' - theoretical, methodological, subject or paradigm specific - required to make sound and informed judgements about an invariably diverse range of projects. This will include the ever more diverse range of qualitative methodologies now utilised to investigate ever more unpredictable social, cultural or political trends within seemingly more 'fluid' and ever changing 'post' or 'late-modern' societies (Giddens, 1991; Bauman, 2000; Lash, 2007; Garrett, 2018). Alongside the dangers of uncertainty, one immediate consequence of any lack of suitable knowledge can remain a propensity for UREC members to be over zealous in ensuring that (narrowly-focused) bureaucratic procedures are fulfilled. This may be alongside a tendency to focus upon the practical ramifications of research methods utilised. Such priorities mean that the nuanced complexity of moral or ethical ramifications attached to research can quickly become marginalised in contrast to 
other organisational agendas (Haggerty, 2004; Hammersley, 2009; Holmwood, 2010; Craig et al, 2014; Ferreri and Glucksberg, 2016).

Other practical problems relating to ethical governance may generate further problems for qualitative researchers within social work. Douglas (1986) has previously argued that seemingly unethical traits such as evasion, deception or dishonesty are necessary in order to adequately study complex social issues, including if they have a strong political dimension. For example, during some types of naturalistic or 'dirty field research' such as ethnography, or types of risky, innovative or social justice related research. A study, as example, which seeks to examine alleged abuse within a residential care home for older people with latestage dementia may demand some forms of dishonesty or other such clandestine methods. Practically this may be in order to fulfil basic research objectives, or indeed to adequately examine a problem recognised as increasingly common in some health and social care sectors (for example, Care Quality Commission, 2013a; 2013b). Parker and Ashencaen Crabtree (2014: 29) have noted some of the moral nuances, complexity and benefits of utilising covert research such as ethnography to examine adult protection and safeguarding issues. The authors argue that covert methods can help to extend our knowledge base to 'uncover truths' which 'need to be heard': including of the possible abuse or neglect of adults within residential or hospital care. They add that covert methods are more likely to be supported ethically by personal moral reflexivity alongside epistemological support from a more situated ethics, which each better reflect moral context and can adapt to ongoing changing ethical dilemmas within unpredictable and fluid fields of research. Despite this, covert methodologies typically struggle for legitimacy and acceptance within many committee-based 'rigid one-size-fits-all ethical review protocols'. 
Similarly, within social work other vulnerable groups such as children placed into residential care may be prioritised for empirical investigation, in order to extrapolate or better understand any complex cultural and socio-political dynamics which influence the quality of care they receive. Alderson (1995), however, argues that young children are much more likely to be deemed too vulnerable to engage in research by most URECs. In relation, Adler and Adler (2002) and Holmwood (2010) ask if some forms of in-depth (yet crucial) qualitative research now face outright censorship from over-zealous committees. Clearly the creativity, enterprise and intelligence on which the study of more uncertain, implicit, messy or complex social needs are often based continues to remain under strain.

\section{Reductive research within the neo-liberal university?}

An assumption is commonly made that universities provide a bedrock for informed debate and open learning, principles which are supported by thought provoking, innovative and democratic research. Such high ideals have, nevertheless, been under strain for some time, and indeed have been challenged. Bailey (2014: 3), for example, has detailed the development of a paradoxical state-controlled yet marketized higher education system in the UK, first initiated by the nascent neoliberal policies of Margaret Thatcher. Alongside intense government regulation and increased competition between institutions, instrumental initiatives such as the research assessment exercise (RAE) have created a didactic yet haphazard means of assessing the quality of research. In addition, ensuing bureaucratic ventures such 
as the Research Evaluation Framework (REF) have continued to prioritise evidencebased empirical research and income generation, whilst closely controlling and restricting the production of knowledge in a system which retains 'enduring parallels to a Soviet planned economy'. Such policies seek to narrow, restrict and control the focus of research. In relation, Mountz and colleagues (2015: 1236-1240) have drawn from the ethics of care to question the 'isolating effects' of the modern 'neo-liberal university'. This includes its seemingly obsessive drive to promote competition, efficiency, status and the maximisation of enterprise and research income. This seemingly oppressive culture can lead to a ruthless drive for staff to achieve narrow social and pedagogical goals, which includes a managerial enforced push to prioritise 'high productivity in compressed time-frames'. Within such environments, learning and research can sometimes be reduced to a series of mechanical administrative processes, which are monitored by close supervision and audit, thereby undermining the core pedagogical principles of personal and collective reflection, alongside more gradual, open and critical learning (see also Ball, 2012; Ferreri and Glucksberg, 2016). The emergence of overtly bureaucratic URECs, and their narrowly focused tendency towards audit and the close control of 'outputs', can be seen as potentially offering an important administrative technology which fortifies any such neoliberal business-orientated model of close staff management alongside sanitized research and learning.

In relation, Hedgecoe (2016: 496) has argued that many URECs rationale now moves beyond ethical governance, to instead offer a platform by which senior management can restrict 'not just what academics say to the press or on their blogs, but what research they do in the first place'. Moreover, ever more narrowly focused science-based or income generating empirical research may limit research activity 
and knowledge production in disciplines such as social work by privileging research that doesn't always link to traditional points of interest and relevance. For example, the increasing emphasis placed upon areas of research which achieve more funding, such as explicitly health-related concerns in relation to dementia or obesity, among other examples. This economically driven political culture can encourage the saturation of research in some areas while many others are bypassed, whatever their importance. Deacon (2000) has previously noted the priority given by Global institutions such as the Organisation for Economic Co-operation and Development (OECD) and the World Bank to welfare states and supporting institutions being opened up to business and private sector provisions wherever possible. Conversely, state welfare provision should instead be narrowed to a bare minimum of support within both health or education sectors, as these industries of sorts have the potential to generate much more income, especially if they are moved into the private sectors. In relation, neoliberal agendas have also been associated politically with an apparent 'post-welfare' emphasis placed upon other policies - such as a call by governments and local authorities for more active citizenship, self-help and individual responsibility (see for example Fenwick and McMillan, 2012; Garrett, 2018). Such policy agendas represent a move away from the state and welfare professionals as embodying aspirations towards social protection or rehabilitation for citizens (for example, Webb, 2006; Wilks, 2011).

Any such narrow priority given to a business model of health care or education is likely to subsequently understate the importance of research in areas such as housing, poverty or discrimination, among numerous other examples. Such ideological and political objectives may again add further institutional obstacles to 
UREC members capacity to appraise the numerous moral uncertainties prevalent if evaluating research applicant's more sensitive proposals.

\section{Privileging realism and biomedicalization}

Social work in the UK and other Western countries has become increasingly drawn into policies that promote a strong narrative of integrative care, despite ongoing service fragmentation within sectors increasingly dominated by the private sectors. This has included much stronger links being built between health care and social work, a model which clearly fits with any emphasis being placed upon welfare being built around the twin pillars of free market-based health and education services (Deacon, 2000; Estes et al, 2003; Carey, 2016a; Carey, 2016b; Whittington, 2016). In many universities in the UK, for example, social work as applied discipline has moved from its traditional base within the Social Sciences to Faculties of Health and Social Care. The formation of health-led 'integrated' teams has also become common within front-line adult social care services, and children's care is again becoming increasingly health-orientated and medicalised (Lymbery, 2010; Wastell and White, 2012; Petrie, 2015; Lilo, 2016). One consequence of such reforms within qualitative research has remained the increased, and sometimes paralysing, influence of medicine and health care upon ethical governance frameworks and committees, including those which affect social work and care (Truman, 2003; Ward and Campbell, 2013; Carey, 2016a). Not uncommonly, it is claimed an overtly narrow focus and priority is now given to research which is empirical and ideally wrapped within positivist and wider realist methodologies. In relation, any such narrow methodological focus leads to distrust, or open scepticism, of research frameworks and topics which wander too far away from a science-orientated and 
evidence-based bedrock. Van den Hoonaard (2001: 19), for example, examined a series of ethical reviews in Canada, the United States and England across the disciplines of anthropology, education, nursing, psychology and sociology. As part of a critique the author highlights strong bias as part of the 'lopsided nature' of reviewing the ethics of research. In particular, there was a tendency for UREC committee members to be dominated by deductively informed quantitative researchers, which resulted in general misunderstanding of many of the inductive methodologies utilised by qualitative researchers. Consequentially, overtly didactic or inappropriate responses influenced many of the judgements made about many qualitative proposals, especially those smaller in scale or without a strong realist foundation to the methodology. Indeed, Van den Hoonaard concludes that the processes of ethical governance within URECs often now resemble the political traits and stages of a 'moral panic' as detailed by Stanley Cohen (1972). In particular, deep trepidation quickly emerged from uncertainty or ignorance on behalf of some reviewers: who subsequently sought to alter, or even close down, projects which stood outside of the more controlled techniques 'realist' methodologies typically use to study very different (and often larger-scale) topics within health care.

Other research findings in social work again suggest ignorance or discursivelyinduced prejudice regarding the complex relationship between ongoing qualitative research processes and some ethical governance techniques. Truman (2003: 7-11), for example, argues that a majority of health care ethical governance processes tend to precede the start of any project, despite ethical issues within qualitative research often emerging 'as research studies unfold'. In Canada, Albert et al (2008) undertook semi-structured interviews with thirty-one biomedical scientists to evaluate their attitudes about the possibility of collaborating with social science and qualitative 
researchers. Whilst a few scientists were receptive, the majority $(n=24)$ were either unreceptive or ambivalent. In particular, there was limited understanding of qualitative methods for research alongside common scepticism felt of the rigour and validity of methods used by qualitative social scientists. As one scientist argued:

It is beaten into every scientist's head. The word rigor is repeated over, over, and over again. It just becomes second nature. You can immediately tell the difference between something that is rigorous and something sloppy. I would say that most surveys, epidemiological studies, and qualitative research are sloppy. They constitute the vast majority of flaky studies.

Whilst qualitative researchers including from social work are present on many URECs within UK universities, the emphasis now placed upon income generation, larger scale empirical research and evidenced-based approaches to attract income, has meant that the ideological push towards the use of positivist methodologies has continued (Dingwall, 2008; Dickson and Holland, 2017). Some social work commentators, nevertheless, question the potential for rigour and validity through any closer links made to positivist, and in turn evidence-based methodologies. Shaw (2016: 27-28), for example, has emphasised a 'fundamental problem' if seeking to utilise positivism as a key paradigm for social work research. Challenges include its lack of capacity to grasp 'social wholes', or indeed the different social emotions, phenomena or contexts which cannot be either observed or accurately quantified (for example, power, discrimination, empathy, and so forth), yet which carry ongoing significance for social work research and practice. There can also remain an apparent lack of meaningful connection with, or use of, social theory, including any workable links to a number of paradigms that help us to explain causality or context. 
This can subsequently undermine analysis, itself the apparent bedrock of so much academic or intellectual research and learning, and lead to constrained, predictable or uninspiring findings. One response to such criticism within health care especially has been to integrate elements of interpretivism into qualitative research, especially the heavy reliance now placed upon elements of phenomenology. With particular reference to disability, Goodley (2011: 56$)$ acknowledges the capacity of phenomenology to help us better understand the 'leib' or physical body related understandings of disability: such as the 'living, feeling and sensing facets of bodily experiences'. However, this alone is not enough, because as master-paradigms phenomenology and interpretivism can sometimes be overtly individualistic and subsequently lack 'a sociological and historical context'. Despite some commentators suggesting helpful ways of challenging this tradition (for example, Larkin et al, 2006), any exclusion of such crucial dynamics, even partial, can significantly undermine analysis, and leave any research project vulnerable to potentially descriptive, anecdotal, biased and conservative interpretations of social realities that neglect political and macro-structural context. Paterson and Hughes (1999), however, identify this as being more about the political nature of some forms of reductive health orientated, biomedical and positivist research. This includes such paradigms' ideological tendency to colonise and hollow out the critical elements of qualitative methodologies such as phenomenology, including their capability to offer more nuanced experiential understandings of personal disadvantage and disability.

Some studies have centred upon tensions which often quickly emerge between the ethical governance concerns identified by health-based ethical committee members when applications are considered (prior to any study beginning), and those of 
qualitative researcher(s) as they begin, and proceed, with any study. Truman (2003: 3-11), for example, has provided a good case example of some of these challenges. The researcher drew upon her 'institutional ethnographic' research to detail problems which prevailed in her attempts to undertake a participative research project involving people with mental health needs. As principal investigator, Truman wished to evaluate a local community-based gym alongside participant co-researchers who regularly accessed this facility. The Local Research Ethics Committee (attached to the NHS) were keen to focus on the core principles of gaining 'informed consent' and promoting 'harm reduction' to participants. According to Truman these priorities are consistent with a biomedical model of research and are embedded within the Social Care Research Ethics Committee at national level (England and Wales). They now also influence many UK URECs. Truman notes, however, that as the project progressed, participant-researcher's personal ethical concerns tended to vary from the twin core bioethical principles of informed consent and harm reduction. In particular, as well as change though the project, the ethical concerns and dilemmas of the participants with mental health needs tended to be more nuanced and complex than the priorities identified by the Committee. They included issues such as those relating to power, changing social relations, the personal values of researchers, inequalities between researchers and co-researchers, as well as the unpredictable yet changing context of the research, including as it proceeded in a typically non-linear and unpredictable fashion. Rather than develop as a series of relatively clear linear or binary ethical concerns, issues such as those relating to 'informed consent' instead tended to shift and modify through active agency and alternating subjectivities for participant co-researchers: 
Many of the users viewed being involved in the research as a way of giving something back to the service. Consent was thus contingent upon the methods we used to enable users to take part in the research along the lines in which they participated within the gym...Some users had become [experienced] researchers, and were undertaking research with others. The boundaries of who was party to informed consent had thus become quite blurred.

Truman (2003: 13) argues that her co-researchers eventually began to 'treat ethical codes as irrelevant', and, within the research field, relied instead upon discussions, collective meetings, personal reflexivity and internal cognitive schemes to resolve ethical dilemmas'. In a similar vein - and as part of their qualitative research into the 'embodied practices' of hairdressing and care for older people with dementia within residential care - Ward and Campbell (2013: 151-152; 162-164) reiterate the disparity between a 'time and labour-intensive' formal application for ethical approval within health care, and their own informal 'ethics journey'. This ethical research passage was strongly influenced by the methodological techniques pioneered by the 'queer' sociologist and critical humanist Ken Plummer. Plummer's distinction between ethical absolutism, or the guidance of research according to firm principles, and situational relativism, in which ethics are produced 'creatively in the concrete situation to hand', were of particular influence to the researchers. The researchers subsequently sought to design and implement a more situated and contextualized response to the many ethical dilemmas they encountered when undertaking research with older people, and which included the use of filming. Similar to Truman (2003) this included more critical individual and group-led discussions and reflections, which helped the researchers to better cope with what was presented as an otherwise clumsy ethical governance 
system 'essentially orientated to positivist scientific medical research'. As part of their conclusion a distinction was drawn between more active and ongoing qualitative methodologies such as ethnography and filming - which seek to better understand the 'performative aspects of everyday living' for people living with Dementia - and the biomedical model which 'privileges measurement over meaning' whilst often being characterized by 'a focus upon the brain and behaviour'.

\section{Risk-aversion and the diminished self}

Traditionally the governance of research ethics has been based around virtues, aspirations towards personal growth, social change and learning, alongside pedagogical training, professionalism and, crucially, mutual trust. Influential ideologies such as Fabianism embraced an idealistic belief in expertise, truth, positive enlightened reform, public servitude and progress. Whatever the limitations of these ideals within our apparent new 'post-paradigm' era, researchers were believed to be more than capable of managing themselves and each other. As Haggerty (2004: 392-395; 411) laments, this model has largely given way to institutionalised forms of risk-aversion, and the ongoing expansion of often invasive bureaucratic regulation. New models based implicitly on 'institutionalized distrust' and micro-surveillance now support a form of 'ethics creep', in which regulatory structures expand outwards to colonize new groups, practices and institutions, whilst intensifying the 'regulation of practices deemed to fall within its official ambit'. Weber $(1930 ; 1946)$, in particular, recognised the tendency for bureaucracies to expand, and indeed take on a life of their own, to sometimes generate unintended and unanticipated rules and regulations. Howard (1994), for example, details how 'rule fetishization' generated by lawyers in the USA has led to decisions that are 'patently 
unjust, unethical, and divorced from common sense' (Haggerty, 2004: 392). Yet today institutional anxieties have also followed violations of trust, among other abuses, within biomedicine rather than the social sciences, and questions remain about the logic of closely monitoring and bureaucratically auditing all research: even if it poses no more risk than encountered in everyday life activities such as 'crossing a road' (Dickson and Holland, 2017: 134).

Some, however, identify the encroachment of regulation, surveillance and institutional distrust as flowing from, and fulfilling, other political agendas. Kemshall (2002: 14), for example, again notes the insipid influence of neo-liberal ideology. This has led to an almost pathological distrust of welfare professionals, and often supposes that professions such as those within the social services remain selfseeking and a risk to political governance. Such anxieties, and others, have promoted cultures of 'risk management' and 'actuarialism' within welfare: including an insurance-based approach to risk in which potential dangers are carefully (yet often crudely) evaluated, assessed, managed through information, aggregated and statistically calculated. Whilst some forms of risk-aversion and surveillance may be exaggerated (see Kemshall, 2010), such changes nevertheless generate pressures upon financially-challenged institutions and professionals, and can lead to greater levels of responsibility, monitoring and distrust. Invariably the often multifarious, unpredictable and potentially precarious projects led by qualitative researchers become yet another possible set of risks to carefully scrutinize and control.

Any risk-averse culture can also move beyond neo-liberal agendas. With regard to subjectivities and notions of trust such as between colleagues, McLaughlin (2008, 131-140) draws influence from Furedi (2004) to propose that in addition to ongoing market-led policy reforms, a series of risk-averse technologies of care, discourses, 
government and media influences and professional theories and models of intervention have led to the construction of the 'diminished self', in which citizens are often crudely or inaccurately identified as perpetually vulnerable, emotionally insecure, weak, exposed, and in need of careful management or therapy (see also Ecclestone, 2007).

Narratives of risk, neglect or abuse are repeatedly generated through a therapeutic industry created in part by various helping professions. Subsequently, a toxic mixture of cultural and political forces ensure that the impression is given that the diminished self remains at risk of stigma, addiction, neglect, bullying, discrimination or harassment. Perhaps inevitably, suspicion of the other fills our consciousness, leading to anxiety, paranoia and distrust. A pathological sub-culture emerges which can include misplaced scepticism felt towards colleagues, subsequently helping to draw attention away from structural inequality or the general incompetence of governments and ruling elites, to instead exaggerate risk at a local level. As McLaughlin (2008: 131) suggests:

The increasing trend to view us all as weak and vulnerable not only heightens anxiety but portrays us all as either abusers or abused. It should perhaps then be no surprise that the end result is a suspicion of both public and professionals, a sense that danger and abuse are around every corner.

Within this insipid political culture, the apparent ethical 'vulnerability' of seemingly passive research participants - alongside any possible risks posed by individual researchers - can quickly become over-stated and exaggerated. As Fisher (2012: 11) adds, locating someone as a member of a vulnerable group, can also be seen as 'an oppressive form of external and arbitrary labelling that denies the [complex] 
plural subjectivities that constitute identity'. Again, the wider impact of macrostructural forces, or inequitable and unethical policy initiatives - including upon research participants and service users - can diminish as meaningful concern.

\section{Conclusions}

Reservations persist about the suitability and indeed purposeful rigour of current ethical governance frameworks effecting social work research. Such processes are often experienced as officious or onerous by qualitative researchers (including in health care and other professions), and indeed now pose a potent threat to the development of any developing research culture within and around the social work profession. At best this may represent a nuisance interpreted subjectively through active agency as overtly formal and bureaucratic. More of a concern, perhaps, remains that ethical governance processes can and indeed do undermine or censor democratic knowledge production within the increasingly risk-averse and politically conservative ideological domains of the neoliberal university. Eagleton (2018: 152153), for example, has recently argued that a centuries-old tradition of universities providing essential 'human critique' is now 'being scuppered by their conversion into pseudo-capitalist enterprises under the sway of a brutally philistine managerial ideology'. This, it seems, has helped to reconstitute the university as an organ of the marketplace, run by administrative technocrats and 'a new intellectual proletariat of academics'. Hedgecoe (2016) adds that elevated risk-aversion relating to ethics governance within UK universities and URECs relates much more to institutional anxieties about the potential damage caused to any universities' reputation within the knowledge economy. Any sincere concern for research subjects therefore is relegated as priority, along with ambitions to generate ethical, innovative and meaningful research which supports understanding and purpose. Precedence is 
instead given to maintaining governance, alongside business and enterprise-related interests, including the capacity of institutions and academics to help maintain the status quo, whilst attracting research funding and completing increasingly myopic research projects as part of the business of education. Yet any political controlling and narrowing of qualitative research within social work will likely have other consequences. Among other examples, these include a negative impact upon more holistic knowledge production, student learning and any capacity to analyse and critique, as well as further strengthening the political ties between social work and other neo-liberal initiatives in the health and social care workplace. This can include the promotion of 'post welfare' government objectives to encourage active citizenship, surveillance and the further retreat of already extensively rationed state support (for example, Kemshall, 2002; Webb, 2006; Scull, 2016). The promotion of codified ethics within social work research have also been linked to integration policies and associated ties to the biomedicalization of social work practice and welfare (Rose and Abi-Rached, 2013, Carey, 2016a; Carey2016b).

Gray (1995: 56) has earlier highlighted the ontological gap not uncommonly evident between codified rules and implicit behavior at the level of agency:

The technical application of moral rules does not necessarily result in ethical behaviour. Moral sensitivity develops from seeing clients in a moral light and being mindful of their value as human beings. It is the product of a special kind of understanding which can be developed only through reflection on, and an appreciation of, the all-encompassing nature of morality. 
Indeed, Bauman (1993) has argued that much of the hard work to be undertaken in any meaningful engagement with ethics remains by the individual and their moral selves - typically in conjunction with people who are in close vicinity (i.e. coproducers, service users, supervisors, researcher(s), participants). Although culturally and politically influenced, morality is perhaps also something to develop, embody and utilize by the individual and collective as meaningful and socially necessary responsibility (for example, Clifford and Burke, 2008; Fisher, 2012; Banks, 2011). Such stances recognise also that trust and academic freedom remain a priority, if relevant including during the co-production of ethical research with research participants. Currently, the hegemonic power of increasingly positive orientated researchers within neoliberal inspired institutions appear instead to be fortified by didactic governance procedures which effectively valorise the careful control of implicitly objectified research subjects (Craig et al, 2014; Carey, 2018). This is clearly something which_perseveres within learning environments in which so much priority is now given to myopic methodologies and topics of investigation, theory displacement, bureaucracy, audit, income generation, managerialism and risk-averse interpretations of reality.

\section{References}

Adler, P.A. and Adler, P. (2002) 'Do university Lawyers and the Police define Research Values?' in Will C. van den Hoonaard (ed.) Walking the Tightrope: Ethical Issues for Qualitative Researchers, Toronto: University of Toronto Press.PP34-42 
Albert, M., Laberge, S., Hodges, B.D, Regehr, G., Lingard, L. (2008) 'Biomedical scientists' perception of social science in health research' Social Science and Medicine, 66 (12): 2520-2531.

Alderson, P. (1995) Listening to Children: Ethics and Social Research Barkingside, Barnardos.

Author (2016)

Bailey, T. (2014) 'Thatcher's enduring legacy to British HE' accessed at https://wonkhe.com/blogs/thatchers-legacy-to-british-universities/ on $20^{\text {th }}$ August 2018.

Ball, S. (2012) 'Performity, Commodification and Commitment: An I-Spy Guide to the Neo-liberal University' British Journal of Education Studies 60 (1): 17-28.

Banks, S. (2011) 'Ethics in an Age of Austerity: Social Work and the Evolving New Public Management' Journal of Social Intervention: Theory and Practice 20(2): 5-23.

Bauman, Z. (1993) Postmodern Ethics Oxford, Blackwell.

Bauman, Z. (2000). Liquid Modernity. Cambridge: Polity. 
Carey, M. (2016a) 'Biomedical Nemesis? Critical deliberations with regard to Health and Social Care integration for Social Work with older people' International Social Work Online First: June 28th

Carey, M. (2016b) 'Journey's end? From residual service to newer forms of pathology, risk aversion and abandonment in social work with older people' Journal of Social Work 16 (3): 344-361.

Carey, M. (2018) 'Some limits and political implications of participation within health and social care for older adults' Ageing and Society FirstView March 16th

Care Quality Commission (2013a) Time to Listen in NHS Hospitals: Dignity and Nutrition Inspection Programmes 2012 Newcastle-upon-Tyne, CQC Care Quality Commission (2013b) Time to Listen in Care Homes: Dignity and Nutrition Inspection Programmes 2012 Newcastle-upon-Tyne, CQC

Clifford, D., and Burke, D. (2008) Anti-Oppressive Ethics and Values in Social Work Basingstoke, Palgrave Macmillan

Cohen, S. (1972) Folk Devils and Moral Panics: The Creation of Mods and Rockers London, MacGibbon and Kee Ltd.

Craig R, Amernic J., and Tourish, D. (2014) 'Perverse audit culture and accountability of the modern public university'. Financial Accountability \& Management 30(1): 1-24.

Crozier, M. (1964) The Bureaucratic Phenomenon London, Tavistock. 
Deacon, B. (2000) Globalisation and Social Policy: The Threat to Equitable Welfare Occassional Paper Number 5, Geneva, United Nations Research Institute for Social Development

Denzin, N.K. (1997) Interpretive Ethnography: Ethnographic Practices for the $21^{\text {st }}$ Century London, Sage.

Denzin, N. K. (2002) 'Social Work in the Seventh Moment', Qualitative Social Work 1(1): 25-38.

Dickson, A. and Holland, K. (2017) 'Hysterical Inquiry and Autoethnography: A Lananian alternative to institutionalized Ethical Commandments' Current Sociology 65(1): 133-148.

Dingwall R (2008) 'The ethical case against ethical regulation in humanities and social science research.' 21st Century Society 3(1): 1-12.

Dominelli, L., and Holloway, M. (2008) 'Ethics and Governance in Social Work Research in the UK', British Journal of Social Work 38(5): 1009-24.

Douglas, M. (1986). Risk acceptability according to the social sciences. London: Routledge and Kegan Paul.

Eagleton, T. (2018) Culture New Haven, Yale University Press. 
Ecclestone, K. (2007) 'Resisting images of the 'diminished self': the implications of emotional well-being and emotional engagement in education policy' Journal of Education Policy 22 (4): 455-470.

Edwards, R., and Mauthner, M. (2002) 'Ethics and Feminist Research: Theory and Practice' in Mauthner, M., Birch, M., Jessop, J., and Miller, T. (eds) Ethics in Qualitative Research London, Sage. Pp14-32.

Estes, C.L., Biggs, S., and Phillipson, C. (2003) Social Theory, Social Policy and Ageing: A Critical Introduction Berkshire, Open University Press.

Fenwick, J. and McMillan, J. (2012). Public participation and public service modernisation: learning from New Labour? International Journal of Public Administration 35(6): 367-376.

Ferreri, M., and Glucksberg, L. (2016) 'Fighting gentrification in the neoliberal university: Displacing communities, researchers and the very possibility of radical critique' Social Research Online 21 (3): 1-7.

Fisher, P. (2012) 'Ethics in qualitative research: 'Vulnerability', citizenship and human rights' Ethics and Social Welfare 6 (1): 2-17.

Furedi, F. (2004) Therapy Culture: Cultivating Vulnerability in an Uncertain Age London, Continuum 
Garrett, P.M. (2018) Welfare Words London, Sage.

Giddens, A. (1991). Modernity and Self-Identity: Self and Society in the Late Modern Age. Cambridge: Polity Press.

Goodley, D. (2011) Disability Studies: An Interdisciplinary Introduction London, Sage

Gray, M. (1995) 'The Ethical Implications of Current Theoretical Developments in Social Work' British Journal of Social Work 25 (1): 55-70.

Hammersley, M. (2009) 'Creeping Ethical Regulation and the Strangling of Research' Sociological Review Online 15416

Haggerty, K.D. (2004) 'Ethics Creep: Governing Social Science Research in the Name of Ethics' Qualitative Sociology 27 (4): 391-414

Hedgecoe, A. (2016) 'Reputational risk, Academic Freedom and Research Ethics Review' Sociology 50(3): 486-501

Holmwood J. (2010) 'Research Ethics Committees (RECs) and the creaking piers of peer review'. Sociological Research Online 15(4): 14.

Houston, S. (2012) 'Engaging with the Crooked Timber of Humanity: Value Pluralism and Social Work' British Journal of Social Work 4 (1): 652-668.

Kemshall, H. (2002) Risk, Social Policy and Welfare Buckingham, Open University Press 
Kemshall, H. (2010) 'Risk rationalities in contemporary social work policy and practice', British Journal of Social Work, 40(4), pp. 1247-62.

Larkin, M., Watts, S., and Clifton, E. (2006) 'Giving voice and making sense in interpretive phenomenological analysis' Qualitative Research in Psychology 3(2): 102120.

Lash, S. (2007) 'Power after Hegemony: Cultural Studies in Mutation?' Theory, Culture, and Society. 24(3):55-78.

Leonard, P. (1997) Postmodern Welfare: Constructing an Emancipatory Project London, Sage

Lewis, J. and Glennerster, H (1996) Implementing the New Community Care ${ }_{2}$ Milton Keynes, Open University Press.

Lilo, E. (2016) Mental Health Integration: Past, Present and Future Liverpool, Health Education North West

Lymbery, M. (2010). A New Vision for Adult Social Care? Continuities and Change in the Care of Older People. Critical Social Policy, 30, 1, 5-26.

McLaughlin, K. (2008) Social Work, Politics and Society, Bristol, Policy Press.

Mountz, A., Bonds, A., Mansfield, R., Loyd, J., Hyndman, J., Walton-Roberts, M., Basu, R., Whitson, R., Hawkins, R., Hamilton, T., and Curran, W. (2015) 'For slow scholarship: A feminist politics of resistance through collective action in the 
neoliberal university' ACME: An international E-Journal for Critical Geographies 14(4): 1235-1259.

Parker, J., and Ashencaen Crabtree, S. (2014) 'Covert research and adult protection and safeguarding: an ethical dilemma?' Journal of Adult Protection, 16(1):1-12.

Parker, M., and Jary, D. (1995). 'The McUniversity: Organization, Management and Academic Subjectivity' Organization 2 (2): 319-338.

Paterson, K., \& Hughes, B. (1999) 'Disability Studies and Phenomenology: The carnal politics of everyday life', Disability and Society, 14:5, 597-610.

Petrie, S. (2015). "Commodifying" children: the impact of markets in services for children in the United Kingdom. International Journal of Child, Youth and Family Studies, 6(2), 275-294.

Rose,N., and Abi-Rached, J.M. (2013) Neuro: The New Brain Sciences and the Management of the Mind Oxford, Princeton University Press

Scull, A. (2015) Madness in civilisation London: Thames and Hudson.

Shaw, I. (2016) Social Work Science Chichester, Columbia University Press 
Truman, C. (2003) 'Ethics and the Ruling Relations of Research Production' $\begin{array}{lllll}\text { Sociological } & \text { Research } & \text { Online, vol. }\end{array}$ http://www.socresonline.org.uk/8/1/truman.html accessed: 3/11/2016

Van den Hoonaard, W, C. (2001) 'Is Research Ethics a Moral Panic?' Canadian Review of Sociology 38(1): 19-36.

Ward, R., and Campbell, S. (2013) 'An Ethics Journey: Ethical Governance of Social Research with Vulnerable Adults and the Implications for Practice' in Carey, M., and Green, L. (eds) Practical Social Work Ethics: Complex Dilemmas within Applied Social Care Farnham, Ashgate. PP151-171.

Wastell, D. and White, S. (2012) 'Blinded by Neuroscience: Social Policy, the Family and the Infant Brain, Families, Relationships and Society 1 (3): 397-414.

Webb, S.A. (2006) Social Work in a Risk Society Basingstoke, Palgrave MacMillan.

Weber, M. (1930) The Protestant Ethic and the spirit of Capitalism London, Allen and Unwin

Weber, M. (1946) From Max Weber: Essays in Sociology London, Routledge and Kegan Paul edited by Gerth, H.H. and C.W.Mills.

Wilks, T. (2011) ‘Ethics and Power: A Discourse’ in Okitikpi, T. (ed) Social Control and the Use of Power in Social Work with Children and Families London, Russell House Publishing 
Whittington, C. (2016) 'The promised liberation of Adult Social Work under England's 2014 Care Act: Genuine Prospect or False Prospectus?' British Journal of Social Work Advanced Access March 10th 